\title{
Erratum to: Who Is the Client and Who Controls Release of Records in a Forensic Evaluation? A Review of Ethics Codes and Practice Guidelines
}

\author{
Bruce Borkosky
}

Published online: 21 February 2015

(C) Springer Science+Business Media New York 2015

Erratum to: Psychol. Inj. and Law (2014) 7(3):264-289

DOI 10.1007/s12207-014-9199-6

Please note that the original version of this article contained the following errors.

1. The note to Table 1 (p. 270) and Table 2 (p. 272) should read: "AAP American Academy of Pediatrics, ABIME American Board of Independent Medical Examiners, ACFE Association of Certified Forensic Examiners, AFCC Association of Family and Conciliation Courts, APS Australian Psychological Society APSAC American Professional Society on the Abuse of Children, ATSA Association for the Treatment of Sexual Abusers, CCE Child Custody Evaluation, CPA Canadian Psychological Association, CST Competency to stand trial, FFD Fitness-for-Duty, LCSWs Licensed Clinical Social Workers, NAFC National Association of Forensic Counselors, NOFSW National Organization of Forensic Social Work, OPA Ontario Psychological Association, SGFP Specialty Guidelines for Forensic Psychology/ists, TPO Third Party Observers"

2. The first mention of 'Test Security' (p. 275, right column, lines 38-48; p. 276, left column, lines 1-3) should have been deleted because it was moved (to p. 279, left column, lines 37-53).

The online version of the original article can be found at http://dx.doi.org/ 10.1007/s12207-014-9199-6.

B. Borkosky $(\bowtie)$

1800 Lakeview Drive, Sebring, FL 33870, USA

e-mail: drborkosky@gmail.com 